\title{
PERBEDAAN KUALITAS TANAMAN MINT (Mentha spicata L) HIDROPONIK DAN KONVENSIONAL BERDASARKAN MORFOLOGI TANAMAN, PROFIL KROMATOGRAM, DAN KADAR MINYAK ATSIRI
}

\author{
Pramita Yuli Pratiwi ${ }^{1}$, Ana Mardiyaningsih ${ }^{2}$, Emi Widarti $^{3}$ \\ ${ }^{1,2}$ Politeknik Kesehatan Bhakti Setya Indonesia Yogyakarta \\ ${ }^{3}$ Rumah Sakit Mardi Waluyo Metro Lampung \\ Email Korespondensi: mardiyaningsihana@gmail.com
}

\begin{abstract}
ABSTRAK
Mint merupakan salah satu tanaman penghasil minyak atsiri. Minyak atsiri Mentha spicata L atau Spearmint banyak digunakan sebagai bahan baku dalam industri makanan, minuman dan sediaan farmasi. Komponen utama spearmint adalah karvon, limonen, cineol, dihidrokarvol, myrcene, dan mentol dengan kadar 0,5\%. Komponen yang terkandung dalam spearmint memiliki khasiat sebagai obat herbal. Pembudidayaan tanaman sangat menentukan hasil bahan obat yang terstandar. Pembudidayaan dengan sistem tanam yang tepat dapat berpengaruh terhadap kualitas simplisia. Penelitian ini adalah penelitian deskriptif untuk membedakan kualitas tanaman Penelitian ini bertujuan untuk mengetahui perbedaan morfologi tanaman, profil kromatogram dan kadar minyak atsiri spearmint dengan sistem tanam yang hidroponik dan konvensionl.

Penelitian ini adalah penelitian deskriptif untuk membedakan kualitas tanaman Mentha spicata L dengan sistem tanam hidroponik dan Mentha spicata L dengan sistem tanam konvensional. Pengamatan morfologi tanaman meliputi ukuran, warna batang dan daun. Kadar minyak atsiri dihitung dari minyak hasil penyulingan dengan metode destilasi uap dan air. Kromatografi lapis tipis minyak Spearmint menggunakan fase diam silika gel F254 dan fase gerak heksan-etil asetat (8:2), penampak bercak $\mathrm{UV}_{254}$ dan penampak bercak anisaldehid $\mathrm{H}_{2} \mathrm{SO}_{4}$.

Morfologi tanaman Spearmint hidroponikdari hasil pengamatan memperlihatkan hasil bahwa ukuran, warna batang dan daun Mentha spicata L sistem tanam hidroponik memiliki perbedaan bermakna. Profil kromatogram tidak memperlihatkan perbedaan jumlah, bercak dan Rf dan intensitas warna salah satu bercak minyak atsiri konvensional lebih tajam. Kadar minyak atsiri hidroponik dan konvensional sebesar $0,0326 \%$ dan $0,0323 \%$ dianalisa dengan statistik Independent T-test tidak memperlihatkan perbedaan bermakna.
\end{abstract}

Kata kunci : Mentha spicata L, minyak atsiri, hidroponik 


\section{ABSTRACT}

Mint is one of the essential oil-producing plants. Essential oils of Mentha spicata $L$ or spearmint are widely used as raw materials in the food, beverage and pharmaceutical preparations industries. The main components of spearmint are karvon, limonen, cineol, dihydrocarvol, myrcene, and $0.5 \%$ menthol. The components contained in spearmint have properties as herbal remedies. Plant cultivation greatly determined the results of standardized drug ingredients. Cultivation with the right planting system can affect the quality of simplicia.

This research were a descriptive study to differentiate the quality of plants. This study aimed to determine differences in plant morphology, chromatogram profile and levels of spearmint essential oil between hydroponic and conventional planting systems. Observation of plant morphology includes the size, color of the stem and leaves. Essential oil content is calculated from refined oil by steam and water distillation method. Spearmint oil was analyzed on thin layer chromatography methode using the silica gel $F_{254}$ as a stationary phase and hexane-ethyl acetate (8: 2) as a mobile phase, with spot visualization under $\mathrm{UV}_{254}$ and anisaldehyde- $\mathrm{H}_{2} \mathrm{SO}_{4}$.

The results showed that the morphology of Mentha spicata L with hydrophonic planting systems had a bigger size in stem and leaves, but the leaves had more bright green than a conventional plant. The chromatogram profile did not show differences in the number of spots and Rf. Mentha spicata L with conventional planting systems had a sharper intensity of color on one of the volatile oil spot, and suggested due to menthol. The levels volatile oil of Mentha spicata $L$ hydroponic and conventional were determined as $0.0326 \%$ and $0.0323 \%$. The Independent T-test analysis showed that there were not a significant differences.

Keywords : Mentha spicata L, essential oil, hydroponic

\section{PENDAHULUAN}

Mint merupakan salah satu tanaman penghasil minyak atsiri. Tiga jenis mint penghasil minyak atsiri yang paling popular yaitu Mentha arvensis L, Mentha piperita L, dan Mentha spicata L. Minyak yang dihasilkan dari Mentha piperita adalah minyak pepermint sedangkan minyak dari Mentha spicata L adalah minyak Spearmint. Minyak atsiri Mentha banyak digunakan sebagai bahan baku dalam industri makanan, minuman dan sediaan farmasi dengan rasa yang khas yaitu sejuk dan menyegarkan. Tanaman Mentha spicata L dan Mentha piperita var crispa berpotensi untuk dikembangkan di Indonesia, hal tersebut dapat dilihat dari banyaknya masyarakat yang membudidayakan tanaman mint. Selain mudah dibudidaya, tanaman mint tidak memerlukan iklim dan tempat tumbuh yang khusus, terbukti mint dapat tumbuh pada dataran rendah maupun dataran tinggi (Sastrohamidjojo, 2004).

Semakin hari, petani terkendala dengan keterbatasan lahan, di industri pertanian Indonesia, ada 33 persen 
wilayah yang dapat digunakan untuk pertanian. Hanya ada 60 juta hektar yang bisa ditanami menjadi wilayah pertanian dan perkebunan (Roslani, 2016). Petani terus berinovasi agar dapat bercocok tanam.

Sistem tanam hidroponik merupakan sistem budidaya tanaman dengan memanfaatkan air nutrisi tanpa menggunakan tanah. Kebutuhan air hidroponik lebih efisien jika dibandingkan dengan sistem tanam konvensional yang menggunakan lahan dengan media tanah yang membutuhkan banyak air, sehingga hidroponik cocok diterapkan pada daerah yang memiliki pasokan air yang terbatas (Alviani, 2016). Hidroponik juga dapat ditanam dengan cara horizontal maupun vertikal,sehingga hidroponik menjadi solusi alternatif untuk mengatasi persoalan bercocok tanam di lahan yang sempit

Menurut Ida Syamsu Roidah (2004) kegiatan usaha pertanian konvensial semakin tidak kompetitif karena tingginya harga lahan, sehingga hidroponik dapat menjadi salah satu solusi bagi lahan terbatas. Hasil penelitian Cristina Sgherri (2010) menunjukan bahwa Oscimum basilicum dengan sistem tanam hidroponik memiliki aktivitas antioksidan yang lebih tinggi daripada yang ditanam secara konvensional. Kedua hal tersebut menguatkan dugaan bahwa sistem tanam hidroponik dapat menjadi solusi yang patut dipertimbangkan dalam industri penyediaan bahan baku simplisia. Oleh sebab itu perlu dilakukan pembuktian kualitas tanaman pada perbedaan sistem tanam. Penelitian ini bertujuan untuk melihat perbedaan kualitas tanaman mint berdasarkan profil morfologi tanaman, kromatogram dan kadar minyak atsiri.

\section{METODE PENELITIAN}

Bahan utama yang digunakan adalah tanaman Mentha spicata L hidroponik dari kebun hidroponik GOODPLANT Ngaglik Sleman, Yogyakarta dan tanaman Mentha spicata $L$ konvensional dari kebun Tani Organik Merapi (TOM), Tegal Sari Pakem Binangun Pakem Sleman Yogyakarta.

Alat destilasi menggunakan seperangkat destilator dengan sistem destilasi uap dan air, corong pisah (Pyrek), vial, beker glass (Pyrek), aquadest (teknis). Alat untuk kromatografi lapis tipis, Bejana KLT, mikro pipet (Scorex), dan sinar UV 254. Bahan untuk pengujian Kromatografi Lapis Tipis adalah Silica gel $\mathrm{F}_{254}$ (Merck), eluen berderajat p.a yaitu Heksana : Etil asetat (8:2), serta penampak bercak anisaldehida- $\mathrm{H}_{2} \mathrm{SO}_{4}$ pekat (p.a).

\section{HASIL DAN PEMBAHASAN}

\section{Identifikasi Kebenaran Spesies Tanaman}

Identifikasi dilakukan melalui determinasi dan identifikasi morfologi luar tanaman Berdasarkan hasil determinasi dapat diketahui bahwa kedua tanaman Mentha spicata L hidroponik dan konvensional yang digunakan adalah Mentha spicata L, Genus Mentha, famili Lamiaceae, ordo Lamiales, kelas magnoliopsida, divisi Magnoliophyta, kingdom Plantae. 
Identifikasi terhadap morfologi berbagai tanaman mint bertujuan untuk mengetahui perbedaan keempat jenis tanaman mint. Hal tersebut dilakukan karena sering terjadi kesalahan dalam penamaan spesies maupun nama dagangnya. Identifikasi perbedaan morfologi dilakukan terhadap empat jenis tanaman yang telah dideterminasi yaitu Mentha spicata L atau spearmint, Mentha piperita var. Crispa,Mentha piperita $\mathrm{L}$, Mentha arvensis $\mathrm{L}$.

Identifikasi dan hasil pengamatan morfologi tanaman mint tersebut dapat dilihat pada Tabel 1.

\section{Perbedaan Morfologi Tanaman Mentha spicata L Hidroponik dan Konvensional.}

Perbedaan morfologi tanaman Mentha spicata L hidroponik dan konvensional diketahui melalui pengamatan terhadap batang dan daun meliputi ukuran dan warnanya. Hasil pengamatan perbedaan morfologi terdapat pada Tabel 2 dan Gambar 1 .

Tabel 1. Identifikasi dan pengamatan empat jenis tanaman mint

\begin{tabular}{ll}
\hline \multicolumn{1}{c}{ Nama Spesies } & \multicolumn{1}{c}{ Ciri- ciri } \\
\hline Mentha spicata $\mathrm{L}$ & $\begin{array}{l}\text { Daun bergerigi, tekstur } \\
\text { kasar dan berbulu }\end{array}$ \\
Mentha piperita var crispa & $\begin{array}{l}\text { Daun bergerigi, tekstur } \\
\text { halus mengkilat dan } \\
\text { berbulu }\end{array}$ \\
Mentha piperita $\mathrm{L}$ & $\begin{array}{l}\text { Bentuk daun oval besar, } \\
\text { batang besar berwarna } \\
\text { ungu, berbulu jelas }\end{array}$ \\
Mentha arvensis $\mathrm{L}$ & $\begin{array}{l}\text { Bentuk daun runcing } \\
\text { seperti tombak berbatang } \\
\text { tegak }\end{array}$ \\
\end{tabular}

Hasil pengamatan memperlihatkan hasil bahwa ukuran batang dan daun Mentha spicata L sistem tanam hidroponik lebih baik dibanding dengan sistem tanam konvensional Mentha spicata L sistem tanam hidroponik memiliki rerata panjang batang $53 \mathrm{~cm}$, diameter batang $0,41 \mathrm{~cm}$, panjang daun $7,8 \mathrm{~cm}$, dan lebar daun 4,8 sedangkan pada Mentha spicata $\mathrm{L}$ konvensional memiliki rerata panjang batang $48 \mathrm{~cm}$, diameter batang $0,31 \mathrm{~cm}$, panjang daun $4,5 \mathrm{~cm}$, lebar 3,1 $\mathrm{cm}$. 
Perbedaan tersebut diduga oleh jumlah nutrisi dan jumlah air yang berbeda, dimana sistem tanam hidroponik memang ditanam dengan media air sehingga selalu mendapat kecukupan air, serta nutrisinya dapat lebih dikontrol melalui pengukuran padatan nutrisi yang dilarutkan dalam media.

Pengamatan warna tanaman Mentha spicata L menunjukan bahwa batang dan daun pada sistem tanam hidroponik jauh lebih pucat atau memudar dibanding dengan sistem tanam konvensional. Perubahan warna pada tanaman hidroponik dapat disebabkan karena kekurangan sinar matahari, kekurangan nutrisi atau bisa juga karena kelebihan air. Kelebihan air dapat menyebabkan perakaran terendam sehingga suplai oksigen pada tanaman berkurang, akibatnya batang dan daun pucat serta tanaman memiliki karakter mudah layu (Ihsan, 2016).

Tanaman konvensional, dapat mengambil nutrisi berupa unsur makro dan mikro yang lebih lengkap dari tanah, yang bagaimana pun merupakan habitat asli tanaman, sehingga menyebabkan intensitas warna hijau lebih pekat.

Tabel 2. Perbedaan morfologi tanaman Mentha spicata L sistem tanam hidroponik dan konvensional

\begin{tabular}{lll}
\hline Parameter yang diamati & \multicolumn{2}{c}{ Perbedaan Morfologi } \\
\cline { 2 - 3 } & Hidroponik & Konvensional \\
\hline Ukuran Batang & Panjang $53 \mathrm{~cm}$ & Panjang $48 \mathrm{~cm}$ \\
& Diameter $0,41 \mathrm{~cm}$ & Diameter $0,31 \mathrm{~cm}$ \\
Warna batang & Hijau semburat ungu & Ungu \\
Ukuran Daun & Panjang $7,8 \mathrm{~cm}$ & Panjang $4,5 \mathrm{~cm}$ \\
& Lebar $4,8 \mathrm{~cm}$ & Lebar $3,1 \mathrm{~cm}$ \\
Warna daun & Hijau pudar & Hijau pekat \\
\hline
\end{tabular}

Daun biasanya berwarna hijau karena plastida yang disebut klorofil (Tjitrosoepomo, 1989). Menurut Pracaya (2007) perubahan warna daun yang mula-mula hijau atau hijau cerah berubah menjadi kuning disebut dengan klorosis. Klorosis adalah keadaan jaringan tumbuhan, khususnya pada daun yang mengalami perubahan warna akibat kekurangan klorofil, sehingga tidak berwana hijau melainkan kuning atau pucat hampir putih. Perubahan warna yang terjadi disebabkan oleh rusak atau tidak berfungsinya klorofi. Perubahan warna dapat terjadi karena penyakit nonparasit atau penyakit fisiologis yaitu penyakit yang disebabkan akibat kekurangan atau kelebihan unsur hara, air, sinar matahari dan temperatur (Pracaya, 2007). 


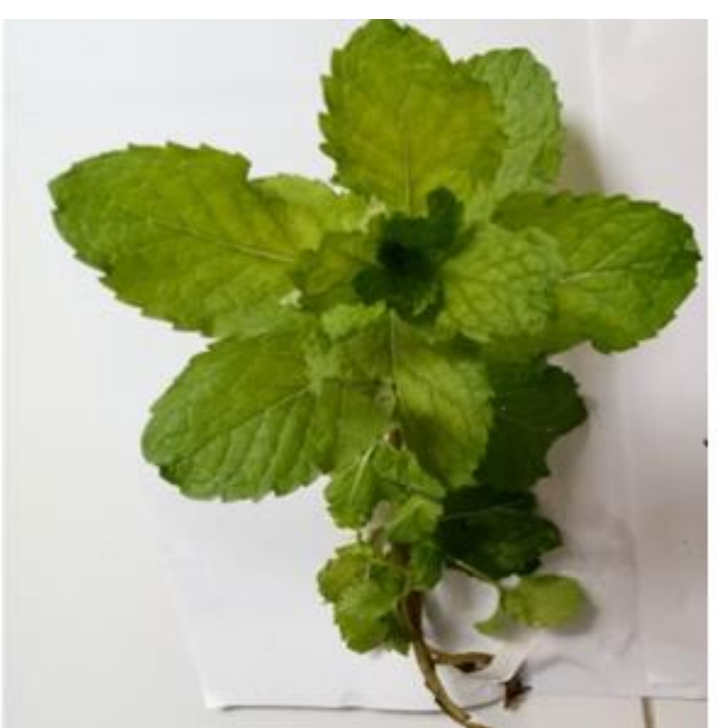

(a)

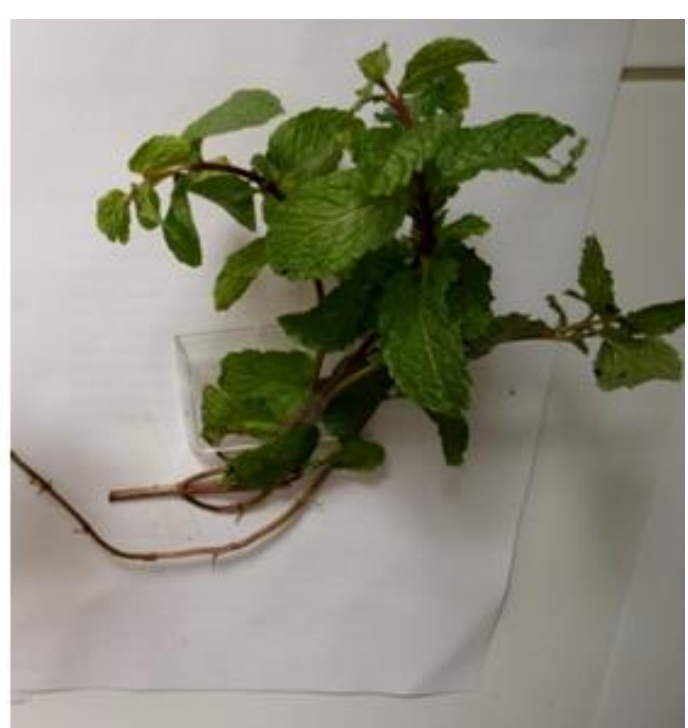

(b)

Gambar 1. Profil morfologi tanaman Mentha spicata L sistem tanam hidroponik (a) dan konvensional (b)

Perbedaan Profil Kromatogram minyak atsiri Tanaman Mentha spicata Hidroponik dan

\section{Konvensional}

Profil kromatogram dari hasil identifikasi minyak atsiri dengan metode kromatografi lapis tipis digunakan untuk melihat perbedaan komponen yang terkandung dalam minyak atsiri Mentha spicata L dari dua jenis sistem tanam yang berbeda. Parameter yang diamati meliputi harga Rf, warna dan jumlah bercak.

Profil kromatogram minyak atsiri Mentha spicata L hidroponik dan konvensional pada 2 kali replikasi pada pengamatan dengan sinar $\mathrm{UV}_{254} \mathrm{~nm}$ dan pada visualisasi Anisaldehida- $\mathrm{H}_{2} \mathrm{SO}_{4}$ menunjukan adanya 4 bercak dengan harga Rf kurang lebih sama. Harga Rf minimal sebesar 0,53 dan maksimal sebesar 0,94. Warna setiap bercak pada Rf yang sama juga tidak menunjukkan perbedaan. Profil warna kromatogram pada penampak bercak Anisaldehida $\mathrm{H}_{2} \mathrm{SO}_{4}$ mulai dari $\mathrm{Rf}$ yang terkecil yaitu biru-ungu, kuning-orange dan merah. Profil kromatogram minyak atsiri Mentha spicata L dapat dilihat pada Gambar 2 .

Minyak Mentha spicata L. mengandung beberapa unsur pokok minyak atsiri Mentha spicata L atau spearmint terdiri dari karvon 45-60\%, limonen, dihidrokarvol, myrcene, 1,8 sineol, 3-oktil asetat, 3-oktanol, transsabinen hidrat, trans-karvol, cis-karvol, alpa-pinen, beta-pinen, linalool, ester, dan keton dan mentol dengan kadar 0,5\% (Lawrence, 2006)

Michael (2008) menyebutkan bahwa senyawa yang paling dominan pada minyak atsiri Mentha spicata L adalah karvon dengan warna bercak kuning-orange dan mempunyai Rf 0,94 0,98 dan Wagner (1984) menyebutkan bahwa warna bercak karvon adalah orange sampai merah-violet. Berdasarkan warna bercak orange sampai merah violet pada profil gambar 1 pada pada tanaman Mentha spicata $\mathrm{L}$ hidroponik dan konvensional dengan 
Rf3 0,81 dan Rf4 0,94 diduga keduanya adalah senyawa karvon. Bercak dengan Rf2 0,63 dan Rf1 0,53 diduga senyawa monoterpen alkohol/ester yaitu mentol karena warna bercak biru menunjukan mentol (Stahl, 1985). Secara kualitatif tidak ada perbedaan kandungan minyak atsiri Mentha spicata pada kedua sistem tanam tersebut. Perbedaan yang ditemukan adalah pada intensitas warna Rf3 pada tanaman Mentha spicata L konvensional lebih tajam dibanding dengan Mentha spicata L hidroponik.
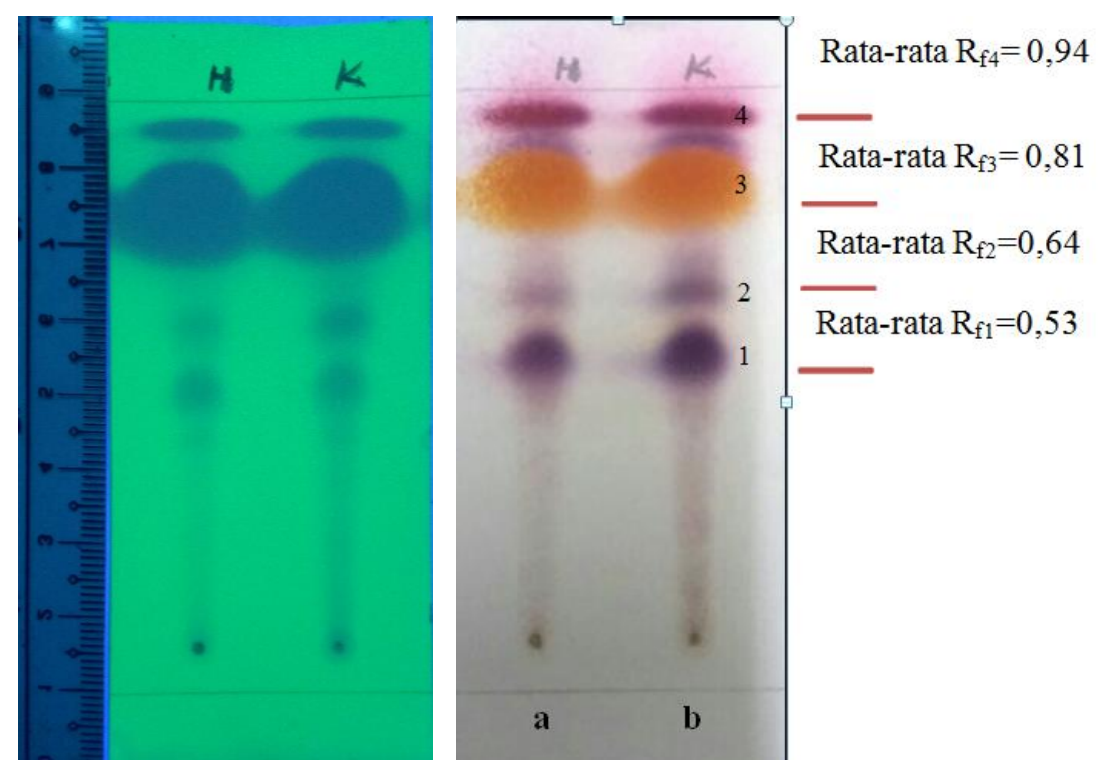

Gambar 2. Profil kromatogram minyak atsiri dengan visualisasi sinar $U^{254}$ dan sinar tampak pada Mentha spicata L sistem tanam hidroponik (a) dan konvensional (b)

\section{Perbedaan Kadar Miyak Atsiri \\ Tanaman Mentha spicata L} Hidroponik dan Konvensional

Hasil pengukuran kadar minyak atsiri yang diperoleh baik hidroponik maupun konvensional menunjukkan perolehan rata-rata $0,0326 \%$ dan $0,0323 \%$. Analisis menggunakan statistik Independent T-test menunjukan tidak adanya perbedaan kadar yang bermakna dari kedua sistem tanam tersebut, seperti data yang terlihat pada Tabel 3. Pada penampak bercak Anisaldehida $\mathrm{H}_{2} \mathrm{SO}_{4}$ rata-rata sama mulai dari $\mathrm{Rf}$ yang terkecil yaitu biruungu, kuning-orange dan merah.

Tabel 3. Hasil pengukuran kadar minyak atsiri Mentha spicata $\mathrm{L}$

\begin{tabular}{ccccccc}
\hline \multirow{2}{*}{ Data } & \multicolumn{5}{c}{ Perbedaan Sistem Tanam } \\
\cline { 2 - 7 } & \multicolumn{3}{c}{ Hidroponik } & \multicolumn{3}{c}{ Konvensional } \\
\cline { 2 - 7 } & 1 & 2 & 3 & 1 & 2 & 3 \\
\hline Bobot Bahan Segar(gram ) & 1000 & 1000 & 1000 & 1000 & 1000 & 1000 \\
Bobot Minyak ( gram ) & 0,33 & 0,33 & 0,32 & 0,33 & 0,33 & 0,31 \\
Kadar Minyak ( \% ) & 0,033 & 0,033 & 0,032 & 0,033 & 0,033 & 0,031 \\
Rerata Kadar Minyak Atsiri (\%) & & $0,0326 \%$ & & & $0,0323 \%$ \\
\hline
\end{tabular}




\section{SIMPULAN}

Morfologi Mentha spicata L dengan sistem tanam hidroponik lebih baik dibanding dengan sistem tanam konvensional dari ukuran batang dan daun yang lebih besar, namun dari warna daun tanaman konvensional lebih baik karena memiliki warna hijau lebih pekat

Profil kromatogram minyak atsiri Mentha spicata L dengan sistem tanam hidroponik dan konvensional tidak memperlihatkan perbedaan bermakna pada jumlah bercak,warna dan $\mathrm{Rf}$ namun teridentifikasi warna salah satu bercak yang diduga senyawa menthol lebih tajam pada tanaman konvensional.

Kadar minyak atsiri Mentha spicata L hidroponik konvensional tidak memiliki perbedaan bermakna.

\section{UCAPAN TERIMA KASIH}

Tim peneliti mengucapkan terimakasih kepada Lembaga Layanan Pendidikan Tinggi Wilayah $\mathrm{V}$ yang telah mendanai penelitian ini

\section{DAFTAR PUSTAKA}

Alviani, P. (2016) Bertanam Hidroponik Untuk Pemula. $\quad\left(2^{\text {nd }}\right.$ edition). Jawa Barat: Bibit Publisher Depok.

Ihsan. (2016). Penyebab daun kuning tanaman hidroponik dan solusinya. Urban Hidroponik. diakses dari Http://www.Urbanhidroponik.com/2 016/04/penyebab-daun-kuningtanaman-hidroponik-dansolusinya.html
Lawrence, B. M. (2006). Mint The Genus Mentha. United States: CRC Press.

Michael W, Pelter. (2008). Analysis of Peppermint Leaf and Spearmint Leaf Extracts by Thin-Layer Chromatography, Department of Chemistry and Physics, Purdue University Calumet, Hammond.

Pracaya. (2007). Hama dan Penyakit Tanaman. Jakarta: Penebar Swadaya.

Roslani, R. P. (2016). Lahan pertanian di Indonesia hanya 33 persen. diakses dari https://www.viva.co.id/arsip/853182lahan-pertanian-di-indonesia-hanya33-persen

Roidah, I.,S., (2014). Pemanfaatan Lahan Dengan Menggunakan Sistem Hidroponik. Jurnal Universitas Tulungagung Bonorowo.Vol 1 No.2: 43-48

Sastrohamidjojo, H. (2004). Kimia Minyak Atsiri. Yogyakarta: Universitas Gadjah Mada Press.

Sgherri, C. (2010). Antioxidant activity and nutraceuticals in basil Ocimum basilicum cv grown in hydroponics and soil, Food Chemistry: 123(2):416-422 
Stahl, E., (1985) Analisis Obat Secara Kromatografi dan Mikroskopi. Bandung: ITB Press.

Tjitrosoepomo, G. (1989). Morfologi Tumbuhan. Yogyakarta: Gajah Mada University Press.

Wagner. H.,Bladt. S., and Zgainski, E.M. (1984). Plant Drug Analysis: A Thin Layer Cromatography Atlas (Th. A. Scoot Springer Verlag, Trans). Berlin Heidelberg New York Tokyo. 